\title{
UNBROKEN DIGITAL DATA FLOW IN THE BUILT ENVIRONMENT PROCESS - A CASE STUDY IN SWEDEN
}

\author{
P. O. Olsson ${ }^{1, *}$, T. Johansson ${ }^{1}$, H. Eriksson ${ }^{1,2}$, T. Lithén ${ }^{2}$, L.-H. Bengtsson ${ }^{2}$ \\ J. Axelsson ${ }^{3}$, U. Roos ${ }^{2}$, K. Neland ${ }^{2}$, B. Rydén ${ }^{2}$, L. Harrie ${ }^{1}$ \\ ${ }^{1}$ Department of Physical Geography and Ecosystem Science, Lund University, Sölvegatan 12, SE-223 62 Lund, Sweden - \\ (per-ola.olsson, tim.johansson, helen.eriksson, lars.harrie)@ nateko.lu.se \\ ${ }^{2}$ Lantmäteriet - the Swedish mapping, cadastral and land registration authority - (helen.eriksson, thomas.lithen, \\ lars-hakan.bengtsson, ulrika.roos, karin.neland, birgitta.ryden)@1m.se \\ ${ }^{3}$ Sweco, Sweden - josefine.axelsson@sweco.se
}

Commission IV, WG IV/10

KEY WORDS: BIM geodata integration, CityGML ADE, data delivery specifications.

\begin{abstract}
:
An unbroken digital data flow would save substantial resources in the built environment process. In this study, which is part of a larger Swedish project, data delivery specifications and methods to integrate BIM and geodata are developed and tested with the aim to facilitate such an unbroken data flow. The main focus areas of the study are: (1) specifications that enables building permission applications based on BIM data to automate the building permission process, (2) reuse of as-built BIM models to update geodata when a building is constructed and (3) a national Swedish CityGML ADE for buildings. The study shows that building permission applications can be partly automated even though the delivery specifications were in the early stages of development at the time of a performed test case. With fully implemented delivery specifications more regulations can be checked. Furthermore, the study demonstrates how a BIM model can be georeferenced with a standard deviation of the transformation of $3 \mathrm{~cm}$ compared to field measurements performed with a total station. The georeferenced BIM model can then be converted to a LOD2 geodata building model to update existing geodata. Finally, a proposal for a national Swedish CityGML ADE for buildings is presented.
\end{abstract}

\section{INTRODUCTION}

Substantial resources are spent on data creation and management in the built environment process. National mapping agencies and local authorities provide geodata required in the planning and design phases of a building's lifecycle. Architecture, Engineering and Construction (AEC) companies invest large resources on BIM data during the lifecycle of a building. However, even though there is an overlap between the GIS and BIM domains in the built environment, differences between the two domains currently prevent a smooth and fully automated integration; there is a need for methods and data exchange formats that enable integration of BIM and geodata for e.g. urban planning and 3D city modelling (e.g. Ohori et al., 2018).

In Sweden, several ongoing projects aim to design workflows that facilitate improved data exchange between actors in the built environment process under the umbrella program Smart Built Environment (https://smartbuilt.se/in-english/). This study is part of one of those projects and concerns data delivery specifications for some data exchange processes: delivery of 2D and 3D geodata from municipalities to AEC companies, delivery of data for building permit applications as well as as-built BIM data from the AEC companies to the municipalities (Figure 1). These delivery specifications are created in an iterative process where draft specifications are designed and tested in various case studies. The main aims of the project are to:

1) standardize the geodata used for the detailed design of buildings

2) increase the automation level in the building permit process
3) increase the use of BIM models to update geodata (mainly city models)

4) create a proposal for a new Swedish standard for city models.

This paper focuses on aims 2-4. For completeness we provide a background description of aim 1 , but no result are provided. The rest of this paper is structured as follows: In Section 2 we describe the methods developed as well as the (preliminary) results. Then, in section 3, concluding remarks are provided.

\section{METHODS AND RESULTS}

The proposed unbroken digital data flow is illustrated in Figure 1. In line with the first aim, required geodata (including detailed development plans) are delivered to the AEC companies in the BIM format Industry Foundation Classes (IFC). Geodata in IFC format can then be imported into BIM tools used by the AEC companies to facilitate the design of a building according to the regulations already in the design phase (cf. van Berlo et al., 2013).

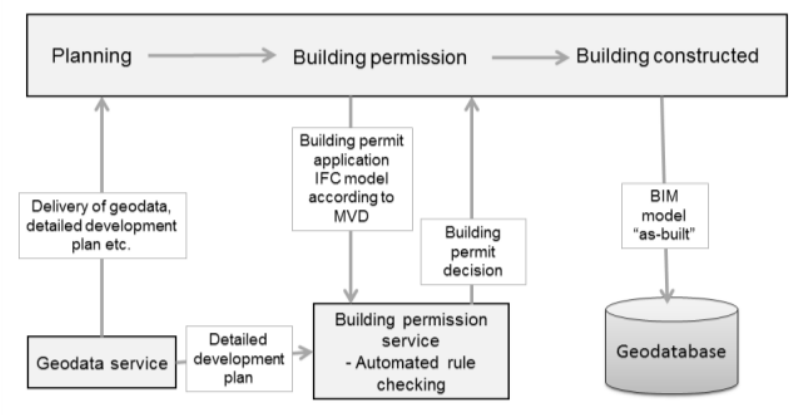


Figure 1. Workflow studied in the project.

When a building is designed, a sub-set of the BIM model is sent to the municipality in IFC format according to a building permit model view definition (MVD) to support aim 2 (increase the automation level in the building permit process). If the building permit is approved the applicant will be informed and the municipality is required to store the building permit BIM model as a legal document. If the application is not approved the applicant is informed about the required changes. Note that the more technical requirements on a building, e.g. fire security, that generally do not require integration with geodata are not considered in this study but will be included in a full-scale building permit application service.

The AEC company continues with the construction of the building as well as creates an as-built BIM model when the construction is finalised. The as-built model is then delivered to the municipality and converted to the national Swedish CityGML ADE (aim 4) to update the existing geodata in the municipality.

The test case of the unbroken digital data flow in this study is performed on an industrial/office building called Myran, located in the municipality of Falun, Sweden. The BIM model of Myran was delivered in IFC format and included a site plan, as IfcSite elements, with an elevation model showing the ground elevation after the construction of the building. This BIM model was in fact created after the construction of the building (by Mondo arkitekter), but due to problems to find a suitable real construction model it was used in this case study. A detailed development plan over the planned location of the building was provided by the municipality of Falun. The development plan was delivered in digital format according to the Swedish standard for digital development plans (SS 637040:2016). Also geodata for the site was provided by the municipality of Falun.

\subsection{Standardize and improve the geodata used for the detailed design of the buildings}

In Sweden a majority of the geodata in the urban environment are provided by Lantmäteriet (the Swedish mapping, cadastral and land registration authority) and local municipalities; but data, such as road, hydrology and geology data from other agencies might be required. The legal documents defining what rules that apply to buildings in an area are determined by the local municipalities as detailed development plans (swe: detaljplan). If required geodata, as well as detailed development plans, are easily accessible in digital format, substantial resources would be saved by the AEC industry in e.g. the planning phase and the building permit application process. A current problem is a lack of standards for these geodata, especially on a municipality level. There has been preliminary work on defining specifications for these data deliveries, but more studies are required to ensure that the information content is sufficient for the AEC companies and also that the data are provided in formats that are easily (and without information loss) imported into BIM tools used by the AEC industry (cf. van Berlo et al., 2013). The plan is to provide standardized geodata and detailed development plans in IFC format to the AEC industry.

\subsection{Increase the automation level in the building permit process}

To enable automated rule checking of building permissions, application services that accepts BIM models should be developed. In this study a partly automated method was implemented with the extract, transform and load (ETL) tool Feature Manipulation Engine (FME) from SAFE Software, Vancouver, Canada (https://www.safe.com/) with the workflow illustrated in Figure 2.

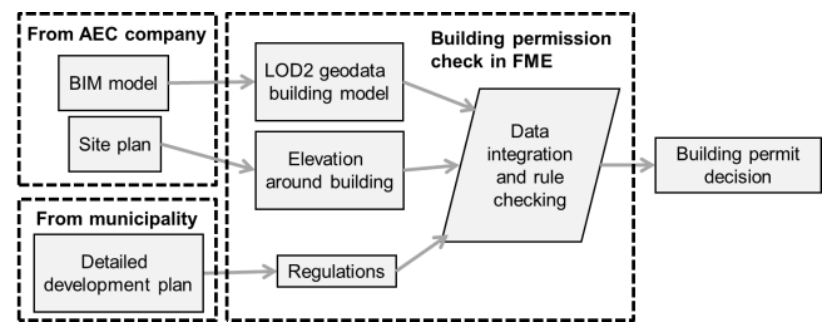

Figure 2. Workflow for data integration and building permit rule checking.

To enable the automated rule checking in this study the BIM model was converted to 3D geodata with a lower level of detail (LOD) than the original BIM model and integrated with the detailed development plan. However, as concluded in several studies (e.g. Ohori et al., 2018) it is nearly impossible to create general methods to convert information rich BIM models to 3D geodata, especially if there are no rules of how the BIM models should be structured. To facilitate the conversion, it is important to use a standardised classification of the IFC elements. In this study some of the most important elements (e.g. IfcWall and IfcRoof) of the building were classified according to CoClass (https://coclass.byggtjanst.se/en/about\#about-coclass). CoClass is a new national Swedish classification system for exchanging and storing information in the entire built environment process, and it will be a requirement of the data delivery specifications for the building permission applications that BIM models are classified according to CoClass. In addition to CoClass, the delivery specifications will be based on a Model View Definition (MVD) of the BIM file. At the time of writing the development of the MVD was in the early stages and no tests could be performed.

In this study the CoClass classification was utilized to identify outer wall and roof elements since only the outer shell of the building is required to create lower level of LOD models. Outer elements could potentially be identified with the property IsExternal in the IFC model but this property is not always used (e.g. Olsson et al. 2018); hence the CoClass classification can ensure that outer walls and roofs are easily identified. The LOD2 geodata building model (Figure 3) was then created by splitting the solid IfcRoof elements into surfaces and identifying the up-looking roof surfaces with the aid of the surface normals. The roof edges coincided with the outer wall surfaces, hence, the outer walls from the IFC model were not required in the creation of the LOD2 geodata model. Instead the wall surfaces in the LOD2 model were added by creating polygons from the edges of the roof surfaces down to the elevation of the IfcSlab element at ground floor. The IFC model was georeferenced so no coordinate transformation was required. 


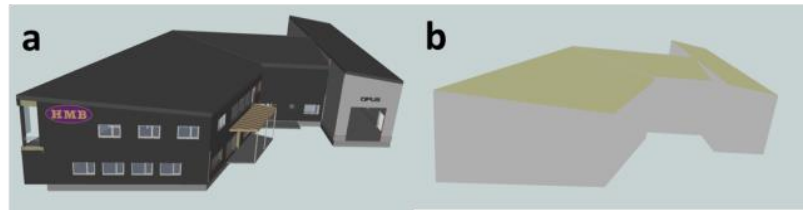

Figure 3. BIM model of Myran (a) and the LOD2 geodata building model (b).

Three regulations in the detailed development plan were tested in this case study: (1) Building height, (2) level of densification, and (3) minimum distance to cadastre boundaries. In Sweden, there is no strict definition stating how to calculate building heights. Some basic rules are given in the Planning and Building Act and the Planning and Building Regulation (swe: SFS 2011:338 Plan-och byggförordningen) but the rules are ambiguous and have led to several legal disputes (Boverket 2014). In this study the building height was calculated according to suggested new guidelines (Boverket 2016) as in Olsson et al. (2018). Due to the simple flat shape of the roof of the building, the height could here easily be calculated as the difference between the highest point of the roof and the mean ground elevation around the building. The highest point of the roof was derived from the LOD2 building model. Mean ground elevation was derived from the site plan; the intersection line between the ground and the building was identified and the mean elevation calculated. The building area was calculated as the area of the footprint of the LOD2 geodata building model.

Building height and building area (densification) were added as attributes to the LOD2 geodata model in FME and the attribute values were checked against the regulation in the detailed development plan i.e. no spatial analyses were involved. Minimum distance to boundaries was checked by creating a polygon representing the area that was allowed to build and overlaying that area with the building footprint to check that the building was entirely inside the allowed area i.e. a spatial analysis was performed.

The building successfully passed all requirements tested. The only regulation in the detailed development plan that could not be tested in this case study was related to the function of the building (sale and repair of cars, non-disturbing industry and offices). The function could not be derived from the IFC model and consequently, it could not be checked with automated methods. However, CoClass includes classes for the function of a building so when CoClass is fully implemented according to the delivery specifications it will be possible to automatically derive the function of a building and check that it is according to the regulations.

\subsection{Increase the use of BIM models to update geodata (mainly city models)}

Laser scanning and photogrammetry are effective technologies for creating 3D city models. However, one shortcoming with airborne observations for updating city models is the long update circle. Quite commonly a city performs laser scanning and/or aerial photography every second to third year. Therefore several researchers have proposed that as-built BIM models could be utilized in the update process (see e.g. Isikdag and Zlatanova 2009; Ohori et al. 2017; Sun et al. 2019) which would contribute to the unbroken digital data flow. In this study we developed and tested methods to convert the BIM model to the city model standard as well as methods to georeference the BIM model.

The conversion of the BIM model was done in FME using an extension of the script described in Olsson (2018). The script was also tailored to create a building LOD2 model in accordance with the new Swedish standard for City models (see next section). Since we only had access to a BIM model created after the construction of the building for this study the conversion in this step was identical to the conversion to the LOD2 building model for the building permit. See section 2.2 and the resulting LOD2 model in Figure 3. At this stage in the project we have not yet made any comparisons of the conversion method used here with other methods. This is planned in a later phase and will be linked to the ISPRS-EuroSDR GeoBIM benchmark 2019 (https://3d.bk.tudelft.nl/projects/geobim-benchmark/, see Noardo, et al. 2019).

A general problem when updating geodata with as-built BIM models is that few BIM models are georeferenced (cf. Ohori et al. 2017) and that the georeferencing often is of inferior quality using approximate geographic coordinates in WGS 84 (in IFC files using e.g. RefLatitude and RefLongitude under IfcSite). The georeferencing in this case was performed by the architect company (i.e., they provided coordinates in the municipality geodetic reference system for the BIM model). This was realised with IfcLocalPlacement and IfcAxis2Placement $3 D$ elements with coordinates and rotations given as IfcCartesianPoint and IfcDirection elements. The coordinate system was not given in the IFC model.

In this study we compared the georeferenced BIM coordinates with coordinates measured by field measurement (total stations) done by the municipality of Falun. The points used for the evaluation were the corner points of the building that could be easily identified in the BIM model and also measured in the field. We performed a unitary transformation (using the geodetic software Gtrans by Lantmäteriet, Sweden) between the field measured coordinates and the outer wall coordinates of the BIM model. The horizontal shift in this transformation is only a couple of $\mathrm{cm}$, and the standard deviation about $3 \mathrm{~cm}$. The same computations using the slab element from the BIM model resulted in similar shift and a standard deviation of $4 \mathrm{~cm}$. A few things should be observed in this study. First that the georeferencing of the architect company was well done (unfortunately, we have not yet received information about how it was done in detail). A second observation is that the difference between the outer wall and the slab element is fairly small in this model.

Based on the experience from our study we would suggest that the as-built BIM model should always be georeferenced based on field measurement of all corner coordinates of the building. When these coordinates are known a unitary transformation should be done between field measured coordinates and the corresponding coordinates in the BIM model. A similarity transformation could be used if the map projection used introduces scale deviations, but ideally the map projection used in a municipality should be locally adjusted so that it is not necessary to introduce scale modelling. From the transformation the origin and direction of the local Cartesian system are estimated; these values should be added to the Eastings, Northings and XAxisAbscissa under IfcMapConversion in the IFC model. This also allows the designer to state the coordinate system if it has an EPSG code. For the conversion of the BIM 
model it is preferable to use the outer wall elements rather than the slab element.

\subsection{Create a proposal for a new Swedish standard for City models}

There is currently no well adopted national standard for city models in Sweden. A national specification for 3D building data, partly built on CityGML and the INSPIRE building theme (see Eriksson et al. 2018) has been developed; however, this specification has not been widely accepted nor implemented. Therefore, in this project we created a proposal for a new Swedish national 3D city model standard. The proposed standard is based on CityGML which is the most comprehensive standard for the exchange of 3D geodata city models today (Liu et al., 2017). Version 3.0 of CityGML was chosen mainly due to its improved interoperability with relevant standards such as IFC, LADM and IndoorGML (Kutzner and Kolbe, 2018). CityGML 3.0 will probably be released by mid2019, but an overview description (Kutzner and Kolbe, 2018), conceptual models and encodings of CityGML 3.0 are already available (https://github.com/opengeospatial/CityGML-3.0).

Even though CityGML is comprehensive, it cannot fulfil all specific requirements on a national level. To overcome this, CityGML allows for schema extensions, Application Domain Extensions (ADEs). ADEs are created as new schemas with their own namespaces, into which the relevant CityGML classes are imported, and where also new classes and attributes can be added. Examples of this are the IMGeo-CityGML, a national 3D standard in the Netherlands realised as a CityGML ADE, that includes national requirements and facilitates the extension from 2D to 2.5D (Stoter et al., 2013); and the CityGML GeoBIM ADE that adds more detailed semantic information from IFC to CityGML (de Laat and van Berlo, 2010).

When planning the implementation of a $3 \mathrm{D}$ city model, one of the first aspects to consider is what the model should be used for and what complexity it should have. That is, what additional textual, semantic and geometric information needs to be included in the model to fulfil the specified requirements. These requirements should, as far as possible, be measurable to enable validation of the implemented model. In this study, an ADE for CityGML 3.0 buildings is created to include additional Swedish requirements such as attributes for name of the building, building area, building classification (CoClass) and additional building information (Figure 4). Linkage to e.g. building permit information, cadastre information, tax information and energy data should also be supported. Of major importance to this project is that the new standard should facilitate the reuse of BIM models (i.e. support the third aim) based on e.g. Olsson (2018).

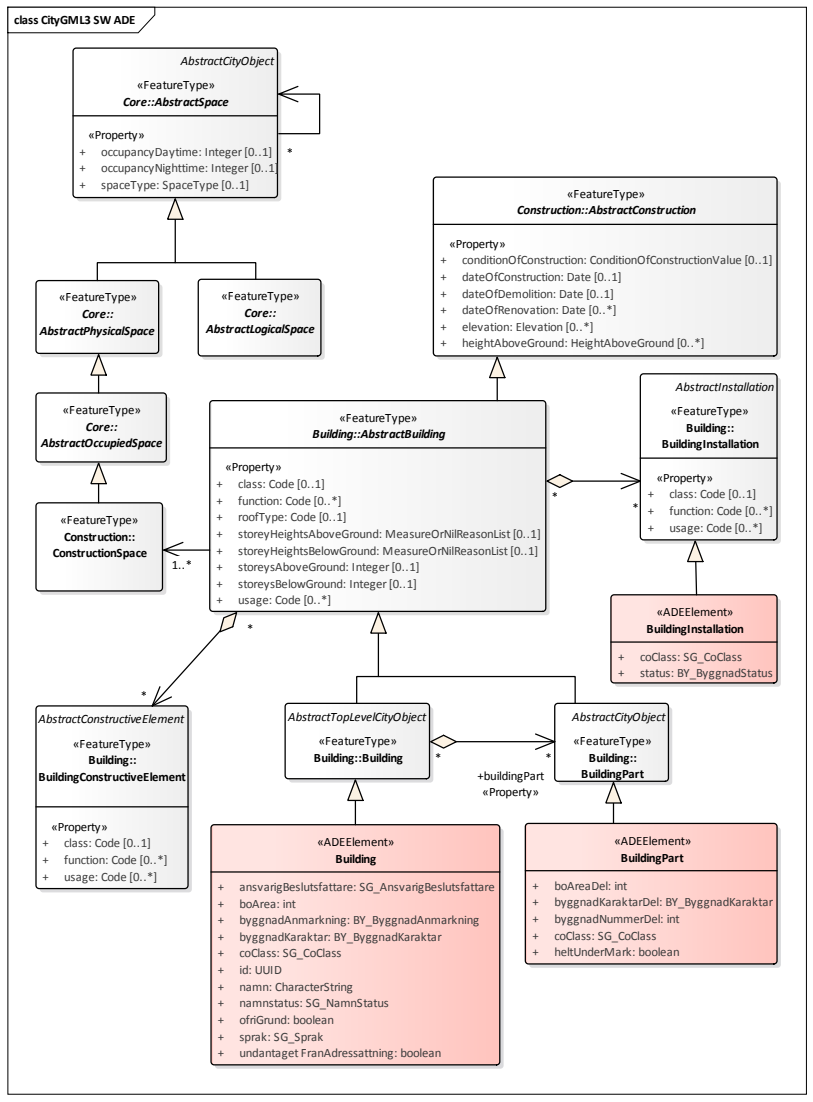

Figure 4. Draft proposal for a Swedish CityGML ADE (red classes are the extensions).

The methodology for creating the CityGML extension is based on the framework described by van Den Brink et al. (2013) and includes the following steps: (1) selection of a formal modelling language (here UML was chosen); (2) definition of the correspondence between classes in the source model and CityGML; (3) decision about which properties and subclasses that should be added; (4) definition of the application code lists. The study also includes the transformation of the UML model to an XSD schema file using ShapeChange (https://shapechange.net/transformations/citygml-transformer/), the mapping of data to the created XSD file, the transformation to GML files and finally, the validation of the GML files. The created GML files will be used to test aim 4 (i.e. increase the use of BIM models to update geodata). The tests are not yet performed, but it is anticipated that the transformation from BIM (IFC) to geodata will be facilitated by the new structure of CityGML 3.0 and this together with additional attributes will contribute to an improved digital information flow within the building permit process.

\section{CONCLUDING REMARKS}

In this study a suggested unbroken digital data flow in the built environment process is presented. The first aim to facilitate the data flow is to create delivery specifications to provide geodata to AEC companies. This aim is not part of the current study, but the plan is to provide required geodata in IFC format to AEC companies. The geodata in IFC format can then be imported to BIM tools to facilitate the design of a building according to the regulations already in the design phase. 
The second aim is to develop delivery specifications that enable automated code checking of building permission applications. A performed test case illustrated how an automated check of regulations according to a detailed development plan in digital format could be implemented to test three regulations: building height, level of densification and minimum distance to boundaries. The only regulation in the detailed development plan that could not be checked in the case study was the function of the building; however, when the delivery specification is fully implemented and a complete CoClass classification of the BIM model is performed, the function of a building can be derived from the BIM model. A requirement for the automated code checking is that the application includes a BIM model in IFC format according to the delivery specifications.

For the third aim (increase the use of BIM models to update geodata) it is of major importance that the as-built BIM model can be transformed to a geodetic reference system with high accuracy. In this study we demonstrated how a BIM model can be georeferenced with a standard deviation of the transformation of $3 \mathrm{~cm}$ compared to field measurements performed with a total station. The results suggest that the BIM model should be georeferenced based on field measurement of all corner coordinates of the constructed building and that a unitary transformation is suitable for the transformation. From the transformation, the origin and direction of the local Cartesian system are estimated; these values should be added to the IFC model as Eastings, Northings and XAxisAbscissa in an IfcMapConversion element. The IfcMapConversion element also allows the designer to include the coordinate system if it has an EPSG code (here EPSG:3013). The georeferenced BIM model can then be converted to a LOD2 geodata building model to update existing geodata.

Finally we designed a suggested national Swedish CityGML ADE that could be used as a Swedish national 3D city model standard to e.g. facilitate updates of geodata with the aid of BIM data.

\section{ACKNOWLEDGEMENT}

This study was financed by the Smart Built Environment project Leveransspecifikationer för Geodata-BIM and the Vinnova project Får Jag Lov. Thanks to many participants in this projects for exchanging ideas and technical work. A special thanks to the municipality of Falun for providing the geodata and the digital development plan and to Mondo arkitekter for providing the BIM model. Free use of the geodetic program Gtrans by Lantmäteriet is acknowledged.

\section{REFERENCES}

van Berlo, L., Dijkmans, T., \& Stoter, J., 2013. Experiment for integrating Dutch 3d spatial planning and BIM for checking building permits.

Boverket, 2014. Rapport 2014:4, Uppdrag Att Utreda Definitioner på Byggnadshöjd, Nockhöjd, Totalhöjd, Vind, Suterrängvåning Och Källare. Available online: http://www.regelradet.se/wp-

content/files_mf/14043797672014_137_Definitioner.pdf (accessed on 22 March 2019).

Boverket, 2016. Rapport 2016:30, Regeringsuppdrag. Exempel på Reglering av Byggnadsverks Höjder Och Våningsantal.
Uppdrag Att ta fram Förslag till Författningsreglering Avseende Vissa Centrala Termer Som Behövs vid Tillämpningen av PlanOch Bygglagen (2010:900). Available online: https://www.boverket.se/contentassets/f92bd42827524152bf66e 6fbb7c75351/exempel-pa-reglering-av-byggnadsverks-hojderoch-vaningsantal.pdf (accessed on 22 March 2019).

Eriksson, H., L. Harrie and J. M. Paasch, 2018. What is the need for building parts? - A comparison of CityGML, INSPIRE Building and a Swedish building standard. The International Archives of the Photogrammetry, Remote Sensing and Spatial Information Sciences, Volume XLII-4/W10, 2018 13th 3D GeoInfo Conference, 1-2 October 2018, Delft, The Netherlands.

Isikdag, U., Zlatanova, S., 2009. Towards defining a framework for automatic generation of buildings in CityGML using building Information Models. In 3D Geo-Information Sciences; Lee, J., Zlatanova, S., (Eds.), Springer, Heidelberg/Berlin, Germany, 79-96.

Kutzner T., Kolbe T., 2018. CityGML 3.0: Sneak Preview, 38. Wissenschaftlich-Technische Jahrestagung der DGPF und PFGK18 Tagung in München - Publikationen der DGPF, Band 27.

de Laat, R., van Berlo, L., 2010. Integration of BIM and GIS: The development of the CityGML GeoBIM extension. Advances in 3D Geo-Information Sciences, 211-225.

Liu X., Wang X.Y., Wright G., Cheng J.C.P., Li X., Liu R., 2017. A State-of-the-Art Review on the Integration of Building Information Modeling (BIM) and Geographic Information System (GIS). ISPRS International Journal of Geo-Information $6,53$.

Noardo, F., Ohori, K. A., Biljecki, F., Ellul, C., Harrie, L., Krijnen, T., Stoter, J., 2019. GeoBIM benchmark 2019: data setup and initial tests, ISPRS Geospatial Week 2019, Enschede, 10-14 June, 2019.

Ohori, K.A., Diakité, A., Krijnen, T., Ledoux, H., \& Stoter, J., 2018. Processing BIM and GIS Models in Practice: Experiences and Recommendations from a GeoBIM Project in The Netherlands. ISPRS International Journal of Geo-Information, 7,311 .

Ohori, K.A., Biljecki, F., Diakité, A., Krijnen, T., Ledoux, H., Stoter, J., 2017. Towards an integration of GIS and BIM data: What are the geometric and topological issues? In ISPRS Annals of Photogrammetry, Remote Sensing and Spatial Information Sciences, Proceedings of ISPRS 12th Geoinfo Conference, Melbourne, Australia, 26-27 October 2017; Copernicus Publications, Gottingen, Germany, 2017; Volume IV-4/W5, 1-8.

Olsson, P.O., 2018. Conversion of an IFC-model to a lod2-3 3D-GIS building model. Agile conference, 12-15 June 2018, Lund, Sweden.

Olsson, P.O., Axelsson, J., Hooper, M., \& Harrie, L., 2018. Automation of Building Permission by Integration of BIM and Geospatial Data. ISPRS International Journal of GeoInformation, 7, 307. 
Stoter J., Ledoux H., Reuvers M., van Den Brink L., Klooster R., Janssen P., Beetz J., Penninga F., Vosselman G. (2013), Establishing and implementing a national 3D standard in The Netherlands, Photogramm.-Fernerkund.-Geoinf., 381-392.

Sun J., Olsson, P.O., Eriksson, H. and Harrie, L., 2019. Evaluating geometric aspects of integrating BIM models into city models. Submitted. 